\section{Validation of the 2019 ACR/EULAR criteria for IgG4-related disease in a Japanese kidney disease cohort: a multicentre retrospective study by the IgG4-related kidney disease working group of the Japanese Society of Nephrology}

IgG4-related disease (IgG4-RD) is a fibroinflammatory condition that can affect various organs. The kidney is one of the organs most frequently affected and IgG4-related tubulointerstitial nephritis (TIN) is the most dominant feature. ${ }^{1}$ However, several radiologically characteristic lesions within the kidney have also been shown to be diagnostic for IgG4-RD affecting the kidney, in the setting of definitively diagnosed IgG4-related lesions in extrarenal organs. ${ }^{2}$ Therefore the term 'IgG4-related kidney disease (IgG4-RKD)' has been proposed as a comprehensive term for the renal lesions associated with IgG4-RD. ${ }^{23}$

In 2011, the IgG4-RKD working group of the Japanese Society of Nephrology proposed diagnostic criteria for IgG4-RKD. ${ }^{4}$ Recently, we validated those criteria in a Japanese kidney cohort and developed a revised version. ${ }^{5}$ On the other hand, the 2019 American College of Rheumatology (ACR)/European League Against Rheumatism (EULAR) classification criteria for IgG4-RD (the ACR/EULAR criteria) were proposed in $2019 .{ }^{6}$ According to the latter criteria, exclusion criteria should be applied first to any potential IgG4-RD case. Then, inclusion criteria consisting of eight weighted domains are applied to any case that does not satisfy any of the exclusion criteria, and if the total inclusion points score is $\geq 20$, the case can be classified as 'IgG4-RD'. We validated the ACR/EULAR criteria in the Japanese kidney cohort used in our validation study for IgG4-RKD 2011..$^{5}$ Briefly, the cohort comprised Japanese patients diagnosed as having renal injury on the basis of urinalysis, radiographic findings and/or function tests between April 2012 and May 2019, in whom serum IgG4 values and/or data for immunohistological staining of IgG4 in renal biopsy samples were known and for whom sufficient clinical information was available. These patients were classified as IgG4-RD or mimickers based on the ACR/EULAR criteria, and the results were evaluated by expert opinion.

Among the 105 patients included, the expert panel diagnosed 55 as true IgG4-RKD and 50 as mimickers. One patient in each group was used for validation of the ACR/EULAR criteria. The clinical and renal pathological features of each group are shown in table 1. In the IgG4-RKD group, renal biopsy was performed in 51 patients and IgG4-TIN was evident in 48 of them (tissue samples being inadequate in 3 ). Of the 48 patients with biopsyproven IgG4-RKD, 34 had extrarenal lesions. Among 14 patients who had only renal lesions, 13 had at least one of the following items: storiform fibrosis demonstrated by renal biopsy, hypocomplementaemia or bilateral renal cortex low-density areas demonstrated by radiology. In seven patients for whom renal histology confirmation was not possible (unavailable in four and inadequate in three), diagnosis of IgG4-RKD was based on radiologically evident bilateral renal cortex low-density areas, in the setting of biopsy-proven IgG4-related extrarenal lesions $(n=6)$ or a definite diagnosis of autoimmune pancreatitis $(n=1)$.

Four of the $55 \operatorname{IgG} 4-\mathrm{RKD}$ patients and 24 of the 50 mimickers had exclusion criteria. Of the remaining cases, 50 of 51 IgG4-RKD patients and 1 of 26 mimickers had an inclusion criterion score of $\geq 20$ points (figure 1 and online supplemental table 1). One
Table 1 Data are available on reasonable request

\begin{tabular}{|c|c|c|c|}
\hline & $\begin{array}{l}\text { IgG4-RKD } \\
(\mathrm{n}=55)\end{array}$ & $\begin{array}{l}\text { Mimicker } \\
(\mathrm{n}=50)\end{array}$ & $P$ value \\
\hline $\begin{array}{l}\text { Age at diagnosis of the kidney disease, } \\
\text { mean } \pm S D \text { (years) }\end{array}$ & $69.9 \pm 9.4$ & $56.7 \pm 17.4$ & $<0.001$ \\
\hline Male (\%) & 76.4 & 44 & 0.001 \\
\hline Allergy (\%) & 27.5 & 36.7 & 0.393 \\
\hline Serum IgG4 (mg/dL), mean \pm SD & $1028 \pm 796$ & $226 \pm 261$ & $<0.001$ \\
\hline $\begin{array}{l}\text { Elevated serum lgG4 ( } \geq 135 \mathrm{mg} / \mathrm{dL}), \mathrm{n} / \\
\text { total }(\%)\end{array}$ & $54 / 55(98.2)$ & $18 / 50(36.0)$ & $<0.001$ \\
\hline Hypocomplementaemia, n/total (\%) & $39 / 55(70.1 \%)$ & $7 / 42(16.7 \%)$ & $<0.001$ \\
\hline $\begin{array}{l}\text { Renal pelvis thickening/soft tissue, } \mathrm{n} / \\
\text { total (\%) }\end{array}$ & $5 / 55(9 \%)$ & $1 / 50(2 \%)$ & 0.20 \\
\hline $\begin{array}{l}\text { Bilateral renal cortex low-density areas, } \\
\text { n/total (\%) }\end{array}$ & $29 / 55(52.7 \%)$ & $7 / 50(14.0 \%)$ & $<0.001$ \\
\hline $\begin{array}{l}\text { Extrarenal organ }(\mathrm{s}) \text { involvement, } \mathrm{n} / \\
\text { total }(\%)\end{array}$ & $41 / 55(74.5)$ & $20 / 50(40.0)$ & $<0.001$ \\
\hline Renal biopsy, performed, n/total (\%) & $51 / 55(92.7)$ & $50 / 50(100)$ & 0.120 \\
\hline Dense lgG4+PC, n/total (\%) & $48 / 51(94.1)$ & $\begin{array}{l}13 / 40(32.5) \\
\text { (not evaluated } \\
\text { in 10) }\end{array}$ & $<0.001$ \\
\hline $\begin{array}{l}\text { Storiform fibrosis in the renal pathology, } \\
\mathrm{n} / \text { total }(\%)\end{array}$ & $28 / 51(54.9)$ & $3 / 50(6)$ & $<0.001$ \\
\hline \multicolumn{4}{|l|}{ Renal pathological diagnosis ( $\mathrm{n}$ ) } \\
\hline & $\begin{array}{l}\text { IgG4-TIN (48) } \\
\text { with MN (4) } \\
\text { with FSGS (1) } \\
\text { with mesPGN (2) } \\
\text { Inadequate } \\
\text { tissue (3) }\end{array}$ & $\begin{array}{l}\text { AAV (8) } \\
\text { MPA (5), EGPA (3) } \\
\text { Idiopathic TIN (5) } \\
\text { Drug-induced } \\
\text { TIN (5) } \\
\text { Nephrosclerosis (4) } \\
\text { Sjögren's } \\
\text { syndrome (4) } \\
\text { Sarcoidosis (3) } \\
\text { MCD (3) } \\
\text { Necrotising GN } \\
\text { without ANCA (3) } \\
\text { MN (3) } \\
\text { Others* (12) }\end{array}$ & \\
\hline
\end{tabular}

Dense IgG4+PC: dense lymphoplasmacytic infiltration with infiltrating lgG4-positive plasma cells $>10 /$ high power field and/or ratio of IgG4-positive plasma cells $>40 \%$ in the renal pathology. Others* ${ }^{*}$ TIN and uveitis syndrome $(n=2)$, TIN associated with inflammatory bowel disease $(n=2)$, TIN with IgM-positive plasma cells $(n=2)$, TIN associated with infection $(n=2)$, IgA nephropathy $(n=1)$, diabetic nephropathy $(n=1)$, malignant lymphoma $(n=1)$ and antibody-mediated rejection after renal transplantation $(n=1)$

AAV, antineutrophil cytoplasmic antibody (ANCA)-associated vasculitis; EPGA, eosinophilic granulomatosis with polyangiitis; FSGS, focal segmental glomerulosclerosis; GN, glomerulonephritis; IgG4-TIN, IgG4-related tubulointerstitial nephritis; MCD, multicentric Castleman's disease; mesPGN, mesangial proliferative glomerulonephritis; MN, membranous nephropathy; MPA, microscopic polyangiitis; TIN, tubulointerstitial nephritis.

IgG4-RKD patient, whose autoimmune pancreatitis was the focal swelling type, was misclassified as non-IgG4-RKD. As a result, 50 of the 55 IgG4-RKD patients were classified as IgG4-RKD and 49 of the 50 mimickers were classified as non-IgG4-RKD (sensitivity $90.9 \%$, specificity $98.0 \%$, positive predictive value 98.0\% and negative predictive value $90.7 \%$ ).

Many IgG4-RKD patients had extrarenal lesions and IgG4positive cell-rich TIN associated with other diseases was effectively excluded on the basis of exclusion criteria. In conclusion, the ACR/EULAR criteria showed an excellent test performance for IgG4-RKD in Japanese patients, although further validation studies of other racial groups will be necessary.

Takako Saeki ๑ , , Tasuku Nagasawa, ${ }^{2}$ Yoshifumi Ubara, ${ }^{3}$ Yoshinori Taniguchi, ${ }^{4}$ Motoko Yanagita, ${ }^{5}$ Shinichi Nishi, ${ }^{6}$ Michio Nagata, ${ }^{7}$ Yutaka Yamaguchi, ${ }^{8}$ Takao Saito, ${ }^{9}$ Hitoshi Nakashima, ${ }^{10}$ Mitsuhiro Kawano 11

${ }^{1}$ Department of Internal Medicine, Nagaoka Red Cross Hospital, Nagaoka, Japan ${ }^{2}$ Division of Nephrology, Endocrinology, and Vascular Medicine, Tohoku University Hospital, Sendai, Japan

${ }^{3}$ Nephrology Center, Toranomon Hospital, Minato-ku, Japan

${ }^{4}$ Department of Endocrinology, Metabolism, Nephrology and Rheumatology, Kochi University, Kochi, Japan 


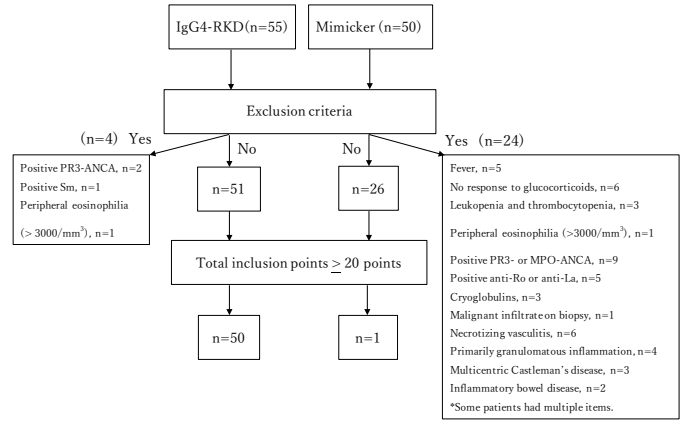

Figure 1 Performance of the American College of Rheumatology/ European League Against Rheumatism classification criteria for lgG4related disease in a Japanese kidney cohort. ANCA, antineutrophil cytoplasmic antibody; IgG4-RKD, IgG4-related kidney disease; MPO, myeloperoxidase; PR-3, proteinase 3.

${ }^{5}$ Department of Nephrology, Graduate School of Medicine, Kyoto University, Kyoto, Japan

${ }^{6}$ Division of Nephrology and Kidney Center, Kobe University Graduate School of Medicine, Kobe, Japan

${ }^{7}$ Kidney and Vascular Pathology, Faculty of Medicine, University of Tsukuba, Tsukuba, Japan

${ }^{8}$ Yamaguchi's Pathology Laboratory, Chiba, Japan

${ }^{9}$ Sanko Clinic, Fukuoka, Japan

${ }^{10}$ Medical Corporation, Souseikai, Fukuoka, Japan

${ }^{11}$ Department of Rheumatology, Graduate School of Medical Sciences, Kanazawa University, Kanazawa, Japan

Correspondence to Dr Takako Saeki, Department of Internal Medicine, Nagaoka Red Cross Hospital, Nagaoka 940-2085, Japan; saekit@nagaoka.jrc.or.jp

Handling editor Josef S Smolen

Contributors All authors made contributions to the conception and design of this study. TSaeki, TN and MK performed the data analysis. TSaeki and MK wrote the manuscript. TSaeki, YU, YT, MY, HN and MK collected the data. All authors contributed to reviewing the manuscript and approved the final version for publication.

Funding This work was supported in part by the committee of the Japanese Society of Nephrology and MHLW Research Programme on Rare and Intractable Diseases (grant number JPMH2OFC1040).

Competing interests None declared.

Patient consent for publication Not required.

Ethics approval The study protocol was initially approved by the ethics committee of Fukuoka University Hospital (reference number 2017M174) and subsequently by the boards of the collaborating institutions.

Provenance and peer review Not commissioned; externally peer reviewed.

This content has been supplied by the author(s). It has not been vetted by BMJ Publishing Group Limited (BMJ) and may not have been peer-reviewed. Any opinions or recommendations discussed are solely those of the author(s) and are not endorsed by BMJ. BMJ disclaims all liability and responsibility arising from any reliance placed on the content. Where the content includes any translated material, BMJ does not warrant the accuracy and reliability of the translations (including but not limited to local regulations, clinical guidelines, terminology, drug names and drug dosages), and is not responsible for any error and/or omissions arising from translation and adaptation or otherwise.

\section{(2) \\ OPEN ACCESS}

Open access This is an open access article distributed in accordance with the Creative Commons Attribution Non Commercial (CC BY-NC 4.0) license, which permits others to distribute, remix, adapt, build upon this work non-commercially, and license their derivative works on different terms, provided the original work is properly cited, appropriate credit is given, any changes made indicated, and the use is non-commercial. See: http://creativecommons.org/licenses/by-nc/4.0/.

(C) Author(s) (or their employer(s)) 2021. Re-use permitted under CC BY-NC. No commercial re-use. See rights and permissions. Published by BMJ.

- Prepublication history and additional material is published online only. To view please visit the journal online (http://dx.doi.org/10.1136/annrheumdis-2020219510).

\section{D) Check for updates}

To cite Saeki T, Nagasawa T, Ubara Y, et al. Ann Rheum Dis 2021;80:956-957.

Received 12 November 2020

Revised 24 December 2020

Accepted 29 January 2021

Published Online First 23 February 2021

Ann Rheum Dis 2021;80:956-957. doi:10.1136/annrheumdis-2020-219510

\section{ORCID iDs}

Takako Saeki http://orcid.org/0000-0002-6666-2571

Mitsuhiro Kawano http://orcid.org/0000-0003-4613-2116

\section{REFERENCES}

1 Saeki T, Nishi S, Imai N, et al. Clinicopathological characteristics of patients with IgG4related tubulointerstitial nephritis. Kidney Int 2010;78:1016-23.

2 Stone JH, Khosroshahi A, Deshpande V, et al. Recommendations for the nomenclature of IgG4-related disease and its individual organ system manifestations. Arthritis Rheum 2012;64:3061-7.

3 Saeki T, Kawano M. Igg4-Related kidney disease. Kidney Int 2014;85:251-7.

4 Kawano M, Saeki T, Nakashima H, et al. Proposal for diagnostic criteria for IgG4-related kidney disease. Clin Exp Nephrol 2011;15:615-26.

5 Saeki T, Kawano M, Nagasawa T. Validation of the diagnostic criteria for IgG4-related kidney disease (IgG4-RKD) 2011, and proposal of a new 2020 version. Clin Exp Nephrol 2021; Jan 4. doi: 10.1007/s10157-020-01993-7.

6 Wallace ZS, Naden RP, Chari S, et al. The 2019 American College of Rheumatology/ European League against rheumatism classification criteria for lgG4-related disease. Ann Rheum Dis 2020;79:77-87. 